\title{
BMJ Open Linkage to primary-care public health facilities for cardiovascular disease prevention: a community-based cohort study from urban slums in India
}

\author{
Abhijit Pakhare (D) , ${ }^{1}$ Ankur Joshi (D) , ${ }^{1}$ Rasha Anwar, ${ }^{2}$ Khushbu Dubey, ${ }^{2}$ \\ Sanjeev Kumar (D) , ${ }^{1}$ Shubham Atal, ${ }^{3}$ Ishan Raj Tiwari, ${ }^{4}$ Vipul Mayank, ${ }^{4}$ \\ Neelesh Shrivastava, ${ }^{2}$ Rajnish Joshi (iD ${ }^{5}$
}

To cite: Pakhare A, Joshi A, Anwar $\mathrm{R}$, et al. Linkage to primary-care public health facilities for cardiovascular disease prevention: a community-based cohort study from urban slums in India. BMJ Open 2021;11:e045997. doi:10.1136/ bmjopen-2020-045997

- Prepublication history and additional supplemental material for this paper are available online. To view these files, please visit the journal online. (http://dx.doi.org/10.1136/ bmjopen-2020-045997).

Received 21 October 2020 Accepted 23 July 2021

D) Check for updates

(c) Author(s) (or their employer(s)) 2021. Re-use permitted under CC BY-NC. No commercial re-use. See rights and permissions. Published by BMJ.

For numbered affiliations see end of article.

Correspondence to Dr Rajnish Joshi; rajnish.genmed@aiimsbhopal. edu.in

\section{ABSTRACT}

Objectives Hypertension and diabetes mellitus are important risk factors for cardiovascular diseases (CVDs). Once identified with these conditions, individuals need to be linked to primary healthcare system for initiation of lifestyle modifications, pharmacotherapy and maintenance of therapies to achieve optimal blood pressure and glycaemic control. In the current study, we evaluated predictors and barriers for non-linkage to primary-care public health facilities for CVD risk reduction.

Methods We conducted a community-based longitudinal study in 16 urban slum clusters in central India. Community health workers (CHWs) in each urban slum cluster screened all adults, aged 30 years or more for hypertension and diabetes, and those positively screened were sought to be linked to urban primary health centres (UPHCs). We performed univariate and multivariate analysis to identify independent predictors for non-linkage to primary-care providers. We conducted in-depth assessment in 10\% of all positively screened, to identify key barriers that potentially prevented linkages to primary-care facilities.

Results Of 6174 individuals screened, 1451 (23.5\%; $95 \% \mathrm{Cl} 22.5$ to 24.6 ) were identified as high risk and required linkage to primary-care facilities. Out of these, $544(37.5 \%)$ were linked to public primary-care facilities and $259(17.8 \%)$ to private providers. Of the remaining, $506(34.9 \%)$ did not get linked to any provider and 142 (9.8\%) defaulted after initial linkages (treatment interrupters). On multivariate analysis, as compared with those linked to public primary-care facilities, those who were not linked had age less than 45 years (OR 2.2 (95\% Cl 1.3 to 3.5)), were in lowest wealth quintile (OR 1.8 (95\% Cl 1.1 to 2.9), resided beyond a kilometre from UPHC (OR $1.7(95 \% \mathrm{Cl} 1.2$ to 2.4$)$ and were engaged late by $\mathrm{CHWs}$ (OR $2.6(95 \% \mathrm{Cl} 1.8$ to 3.7)). Despite having comparable knowledge level, denial about their risk status and lack of family support were key barriers in this group.

Conclusions This study demonstrates feasibility of CHWbased strategy in promoting linkages to primary-care facilities.

\section{INTRODUCTION}

Hypertension and diabetes mellitus are important risk factors for cardiovascular

\section{Strengths and limitations of this study}

- It is a 'real-world' community-based implementation as per national non-communicable disease control programme in India (known as NPCDCS), which envisages population-based screening through community health workers (CHWs), and linkages to public health facilities.

- This study highlights that within urban slums, being young, in a low socioeconomic position and distance from health facility are important determinants of non-linkage to public health facility.

- Early engagement by CHWs enhances likelihood of linkage.

- This study was limited to urban slum clusters from a single city; however, we believe that health infrastructure is broadly similar in such settings elsewhere.

disease (CVD), and achieving optimal bloodpressure and glycaemic control is challenging. ${ }^{1}$ In urban India, about 30\%-40\% of all adults have hypertension and about $10 \%-15 \%$ have diabetes mellitus. ${ }^{23}$ Only half of all individuals with hypertension are aware of their elevated blood pressures, and of those aware, half are not on any medication. Further, only about half of all individuals with hypertension who are on medication are controlled. ${ }^{4}$ In order to bridge awarenesstreatment control gaps, the Indian National Program for prevention and control of cancer, Diabetes, Cardiovascular diseases and Stroke (NPCDCS) was initiated in the year 2010. This programme envisages to annually screen all adults aged 30 years and above for presence of hypertension and diabetes mellitus, initiate life-style changes and drug therapy in those positively screened, and follow them up for treatment adherence. ${ }^{5}$ Availability and affordability of preventive drug therapies has 
been a key barrier in achieving control of risk factors. ${ }^{6}$ In order to overcome this barrier, NPCDCS has made medications for blood-pressure and glycaemic control available in public sector primary-care facilities. ${ }^{7}$

CVD prevention requires a multi-level approach. Individuals who are identified with hypertension and diabetes mellitus in the community are largely asymptomatic. ${ }^{89}$ At individual level, there is a need to adopt various life-style measures to reduce CVD risk, which requires sustained behaviour change. Cultural acceptance of behavioural change is required at a societal level especially for risk factors such as tobacco use, physical inactivity and dietary practices. Drug therapy for blood-pressure and glycaemic control is an integral part of CVD prevention, and making these available requires health-system-level strengthening. Despite improving availability and affordability of drug therapy, individual-level (related to knowledge, attitude, beliefs and practices) and health-system-level barriers (infrastructure, access and quality of services) remain important. ${ }^{10}$ High-income countries have a much better availability and affordability of anti-hypertensive medication, and their blood-pressure control is better (36\% in high-income vs $23 \%$ in low-income countries). ${ }^{6}$ Individuals with hypertension and diabetes need to be effectively linked to primary-care facilities so that their blood pressures and sugars are controlled, and their CVD risk is lowered. For this linkage to be successful, individual, societal and health-system-level barriers need to be addressed.

Linkage of individuals identified with hypertension and diabetes to primary healthcare facilities is an important step towards CVD risk reduction. It is important to understand which high-risk individuals do not get linked and predictors of non-linkage. We have explored these issues in the current study, where a community-wide screening was performed as envisaged in NPCDCS, and high-risk individuals were sought to be linked to public sector primary-care facilities.

\section{METHODS}

\section{Design and ethics statement}

We designed a community-based longitudinal study to identify predictors of non-linkage to public health primary-care facilities. All participants provided written informed consent prior to initiation of any study procedures. Detailed study protocol is available on pre-print server. $^{11}$

\section{Setting}

The study was conducted in 16 urban slum clusters from a catchment area of two urban primary health centres (UPHCs) of Bhopal, a city located in central India. These UPHCs were located at Barkheda Pathani and Saibaba Nagar which are usual facilities from where study participants sought primary healthcare. Every urban slum cluster has a designated accredited social health activist (ASHA) who functions as a community health worker (CHW) and provides linkages to the public health delivery system. In addition to UPHCs, primary-care needs in public sector are also met by the district hospital and governmentowned medical college hospitals. There are no out-ofpocket costs towards either consultation or available medications at these facilities. Many individuals opt to seek care from the private sector, which is larger both in terms of number of providers, as well as individuals who seek care through it. Every primary-care consultation in private sector incurs out-of-pocket expenditure (range US $\$ 1$ to US $\$ 10$ ), and prescribed medications are available through private pharmacies. Private care providers have longer working hours and could be located in closer proximity to some urban slum clusters.

\section{Participants}

All individuals above 30 years of age and residing in the selected clusters for 6 months or more were eligible for inclusion. Women who were pregnant at the time of screening were excluded. No other exclusions were applied. Participants who met at least one criteria as per high-risk definition (described below) were classified as high risk.

\section{Study procedures}

Detailed study procedures are described elsewhere. ${ }^{11}$ Briefly, these included the following:

\section{CHW recruitment and training}

ASHAs who function as CHWs in each cluster were trained in basic health issues with respect to CVD, its risk factors and their prevention. The training consisted of interview and communication techniques, measuring physical parameters like height, weight, waist circumference (WC), blood-pressure measurement using a digital sphygmomanometer and blood sugar estimation using a glucometer.

\section{Screening for CVD risk factors}

CHWs performed an initial home visit-based screening and administered a questionnaire (to identify tobacco or alcohol consumption, physical activity levels, previously known hypertension, diabetes or a manifest CVD such as ischaemic heart disease or stroke), performed anthropometry (to measure body mass index (BMI) and WC (weighing scale-Seca-876, stadiometer-Seca-213 and measuring tapes-Seca-201; Seca, Hamburg, Germany), and measured blood pressure (using Omron digital apparatus model 7200, Kyoto, Japan) and a non-fasting blood glucose by glucometer (SD Diagnostics, Korea).

\section{Identification of high-risk individuals}

Within 1 week of home visit-based screening, a diagnosis confirmation camp was conducted by the study supervisor to obtain a second set of blood pressure readings and a random blood glucose assessment. We identified individuals with hypertension (previously known hypertension or SBP $>140$ or DBP $>90 \mathrm{~mm} \mathrm{Hg}$ on two or more occasions) ${ }^{12}$ or diabetes (previously known diabetes or 
random blood sugar $>200 \mathrm{mg} / \mathrm{dL}$ or a fasting blood sugar (FBS) $>126 \mathrm{mg} / \mathrm{dL}$ ), or a previously known cardiovascular or a cerebrovascular event, and were classified as high-CVD risk. This high-risk group was followed up over the next 12 months to demonstrate feasibility of CHWbased interventions. Quality of data collected by CHWs was monitored by study supervisors who used to crosscheck $10 \%$ of blood-pressure measurements. Also, the same participants were questioned by supervisors about tobacco usage in order to verify responses collected by CHWs. All CHWs were provided with an android-based mobile phone with installed application based on Commcare (Dimagi Inc, USA) for data collection. This tool had a facility to track visits and details of the previous visits can be made available. We also developed a digital decision support system for identification of individuals at high risk as per the operational definitions. Questionnaires used in the study are available in online supplemental file 1 .

\section{Management of 'high-risk' individuals}

All 'high risk' individuals were advised about tobacco cessation, dietary modification, and increase in physical activity by CHWs and study supervisors. While all individuals were free to seek care from either the nearest UPHC or any other source of their choice, they were provided a referral slip with previous blood pressure and blood sugar values to facilitate subsequent decision-making. If they chose to visit the UPHC, they were evaluated by a physician. UPHC is functional between 12:00 and 17:00 on all weekdays, with 1 day in a week designated as noncommunicable disease clinic (Tuesdays for Saibaba Nagar and Wednesdays for Barkheda Pathani UPHCs). The physicians at UPHC were trained to follow simple therapeutic algorithms for treatment initiation, optimisation and continuation for hypertension (based on JNC 8 hypertension guidelines), ${ }^{12}$ and diabetes (based on ADA guidelines 2017). ${ }^{13}$ Blood pressure of all participants and blood sugar levels of participants were measured at UPHC for reconfirmation and facilitation of treatment decisions. The physician advised either treatment initiation (if they were newly detected with hypertension or diabetes mellitus), treatment optimisation (if they were previously known to have these risks but were not controlled (SBP $>140$ mm Hg; DBP $>90$ mm Hg; FBS $>140$ mg/dL; post-prandial blood sugar $>180 \mathrm{mg} / \mathrm{dL}$ )) or treatment continuation (if they were well controlled on previous therapies). The physicians could choose from available drugs at UPHC which were losartan (angiotensin receptor blocker), amlodipine (calcium channel blocker), hydrocholorthiazide (diuretic), metformin (biguanide), glimiperide (sulphonylurea), low-dose aspirin and atorvastatin. These drugs have also been identified by WHO Package of Essential Noncommunicable Disease Interventions (WHO PEN) as essential ingredients for care. ${ }^{14}$ Individuals were usually dispensed with 15 days of drug therapy and advised for a refill thereafter. Those individuals who would not be optimally controlled on maximal permissible dosages of available drugs despite adequate drug adherence were advised consultation with specialists at secondary or tertiary care hospitals in the public sector. All these treatment decisions (initiation, escalation, de-escalation of drug therapy) were recorded by the study physician in a register available at UPHC for the research project, which also served as visit-log for high-risk participants. Individuals who were linked to UPHC were identified from this register. The data of the register were updated weekly into a designated data collection software by study supervisors. Periodic data quality check was done by study investigators. Those who had three or more visits logged in 6 months from their initial visit at UPHC were classified as 'treatment continuers', and those who had fewer visits were 'treatment interrupters'.

\section{Follow-up visits by CHWs and outcome classification}

Subsequent to initial screening, CHWs performed home visits once in every 2 months to reinforce linkages to public health facilities and adherence to drug treatment. It was expressed as percentage of consumed pills. In the 6-month home visit (third visit), CHWs again recorded source of CVD-prevention treatment, and identified individuals who were 'not on treatment', 'on treatment from private care providers', and 'treatment continuers' or 'treatment interrupters'. Based on this information and treatment records available from UPHC register, all high-risk individuals were classified into four groups: group A, linked to public sector primary-care facilities and treatment continuers; group B, linked to private care providers and treatment continuers; group C, linked to public or private sector primary-care facilities and treatment interrupters; group D, not linked to any provider.

\section{Patient and public involvement}

This study was implemented through community health workers (ASHAs) who reside in the same community. These community mobilisation meetings were organised by CHW of the concerned area and medical social worker (project supervisor) and were attended by study investigator (s). These meetings ensured cooperation of public for the conduct of study.

\section{Operational definitions}

Optimal blood pressure control was defined as SBP $<140$ and $\mathrm{DBP}<90 \mathrm{~mm} \mathrm{Hg} .{ }^{12}$

Optimal glycaemic control was defined as FBS $<126 \mathrm{mg} /$ $\mathrm{dL}$ and post-prandial blood sugar $<180 \mathrm{mg} / \mathrm{dL}$ or HbAlc $<7 .{ }^{13}$ 'ASHA engagement' has been classified based on the home-visit to confirmation camp-visit interval. Confirmation visit happening within 7 days has been defined as 'early engagers', between 1 week and 1 month were 'intermediate', and beyond 1 month were 'late engagers'. Outcome was classified in terms of the participants being linked to public health facilities, or linked to public health facilities but interrupted, or linked to private health facilities, or not linked to any facilities. 


\section{Sampling for identification of barriers to linkage}

Barrier identification was done after 12 months of baseline assessment. For exploring facilitators and barriers of linkage, a semi-structured questionnaire was prepared which has items categorised into different domains (Knowledge, Attitude, Individual, Health Provider and Health System). Respondents had to indicate whether a particular item is applicable to them or not. This questionnaire was designed based on literature review and discussion among investigators and other study stakeholders. It was pilot tested on few participants and suitably modified. It also has open-ended questions about reasons for non-linkage. This questionnaire was administered to sub-sample from each category of participants. For this, we performed a stratified random sampling and listed numerically proportionate individuals from each of the four groups A, B, C and D, ensuring a sample size of $10 \%$ from each group.

\section{Statistical analysis}

All data analysis was done using SPSS software V.23.0. Wealth index was constructed by using principal component analysis on household asset ownership data. ${ }^{15}$ Households were classified in different wealth quintiles; a higher wealth quintile indicates relatively better socioeconomic position. Distribution of continuous variables across linkage groups was compared using ANOVA and dichotomous variables using $\chi^{2}$ test. A $p$ value of $<0.05$ was considered as significant for these comparisons. To determine predictors of non-linkage and linkage to private facility, individuals in group A (linked to public health facilities) were considered as reference. Considering more than two categories of outcome variable (Linkage Status), we used multi-nominal logistic regression model to identify variables independently associated with nonlinkage, linkage to private facilities and interrupters after linkage with reference to linkage to public health facilities. OR was estimated to represent point estimate and its 95\% CI as a measure of precision of the association. We performed a descriptive analysis of the barriers in each of the domains and for individuals in each of the outcome categories.

\section{RESULTS}

Between November 2017 and June 2018, a total of 6174 individuals were screened, and 1451 (23.5\%; 95\% CI 22.5 to 24.6) were identified as high risk. This was a baseline assessment as depicted in study flow (figure 1). Most of these individuals were middle aged and women $(\mathrm{n}=858$, $59.1 \%)$. Six months after initial screening, $803(55.2 \%)$ of all high-risk individuals were linked and continued their treatments. Of 1451 high-risk participants,544 (37.5\%) were linked to public health facilities (group A) and 259 $(17.8 \%)$ to private care providers (group B). Another

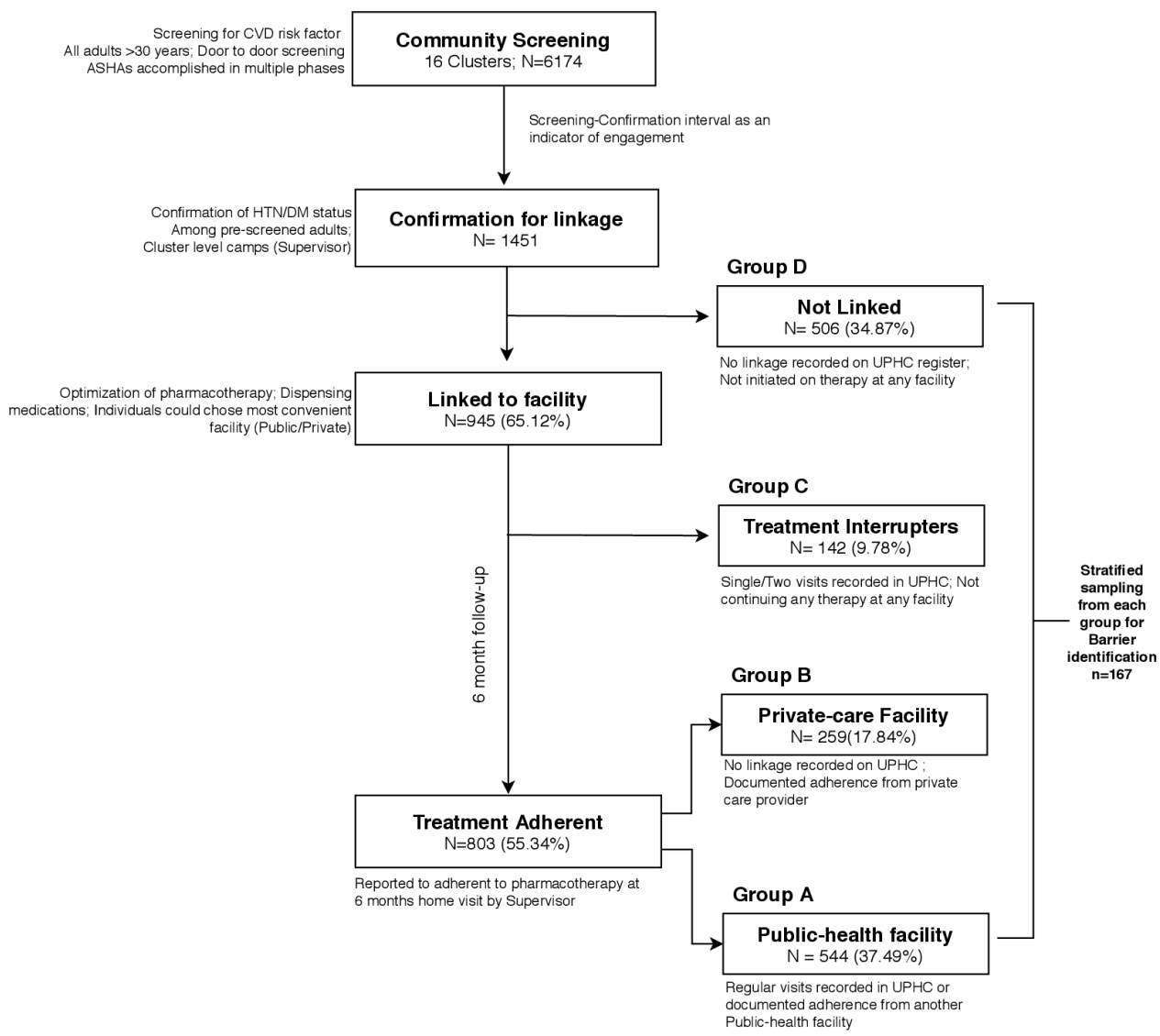

Figure 1 Study flow. ASHA, accredited social health activist; CVD, cardiovascular disease; DM, diabetes mellitus; HTN, hypertension; UPHC, urban primary health centre. 
$142(9.8 \%)$ were treatment interrupters (group C), and $506(34.9 \%)$ never got linked to any provider (group D). Most individuals in group A (linked to public facilities) were of age more than 45 years $(69.3 \%)$, were women
$(67.8 \%)$, lived within $3 \mathrm{~km}$ of UPHC $(72.6 \%)$ and did not use tobacco $(60.1 \%)$. About half of them $(44.9 \%)$ were engaged early by ASHAs. Characteristics of individuals in these four groups are presented in table 1 .

Table 1 Distribution of sociodemographic, risk factors, measurements and classification based on linkage status

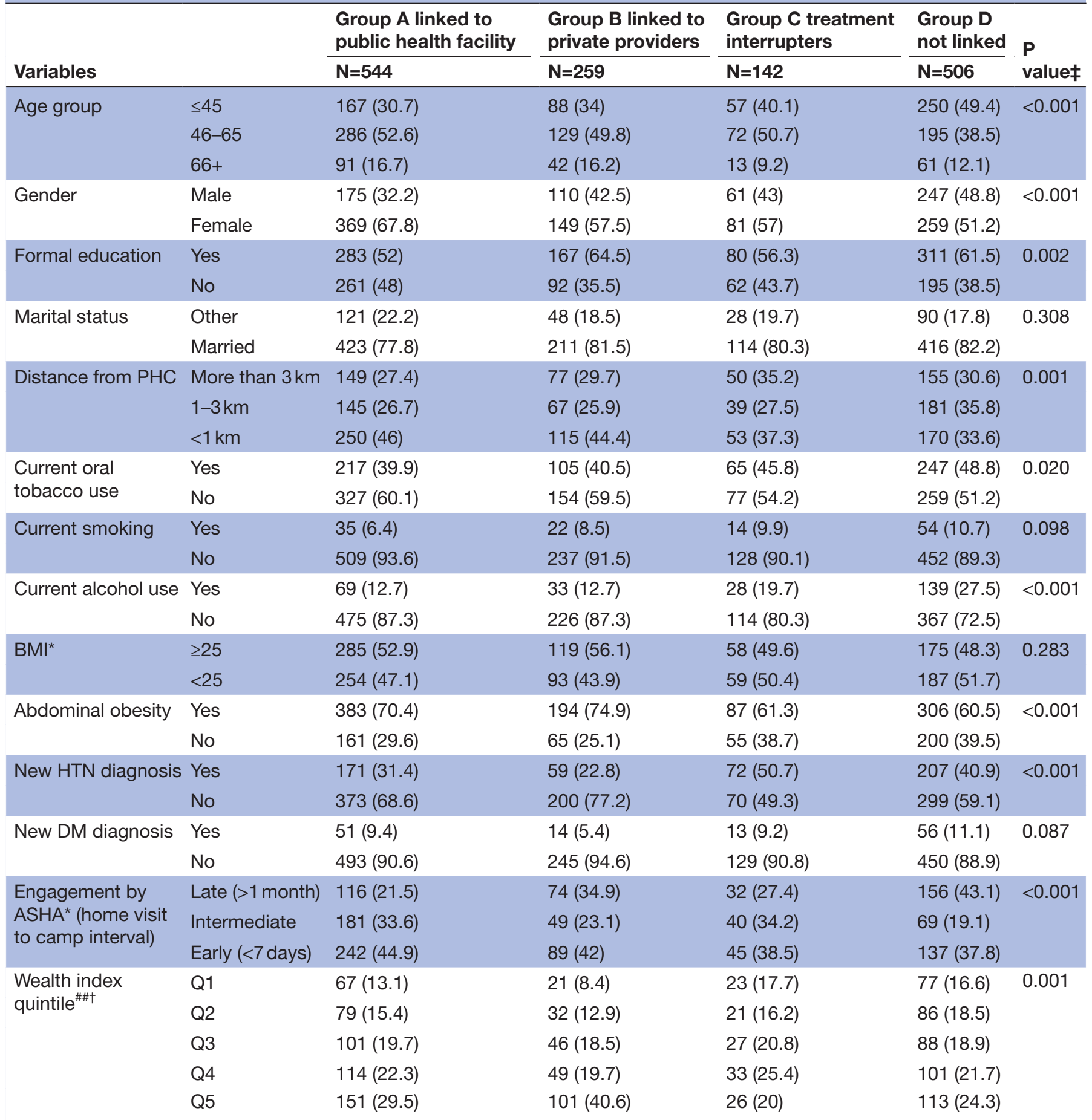

All numbers indicate frequency (proportion) unless indicated otherwise.

Formal education - any level of formal education in school; tobacco use-use of any tobacco product in the last 30 days; abdominal obesity - waist circumference more than $90 \mathrm{~cm}$ for men and $80 \mathrm{~cm}$ for women.

${ }^{*}$ Data are missing for 221 participants $(5,47,25$ and 144, respectively, in groups A, B, C and D). †Data are missing for 95 participants $(32,10,12$ and 41 , respectively, in groups $A, B, C$ and $D)$. $\ddagger$ Chi-square test for indepndence/association

ASHA, accredited social health activist; BMI, body mass index; DM, diabetes mellitus; HTN, hypertension; PHC, primary health centre. 
As compared with those who were linked to public health facilities, those who never got linked (group D) were more likely to be young (OR 2.2 (95\% CI 1.3 to 3.5$)$ ), in lowest wealth quintile (OR 1.8 (95\% CI 1.1 to 2.9)) and consumed alcohol (OR 1.9 (95\% CI 1.3 to 3.0)). These individuals also engaged late with CHWs (OR 2.6 (95\% CI 1.8 to 3.7)) and lived farther away from UPHC (OR 1.7 (95\% CI 1.2 to 2.4)). These risk estimates are derived from multi-nominal logistic regression analysis. Goodness of fit was statistically non-significant $(\mathrm{p}=0.906)$, and likelihood ratio test for model fitting criteria was statistically significant $(\mathrm{p}<0.001$; Cragg-Uhler (Nagelkerke) $\mathrm{R}^{2}=0.623$ ). This model fitting information indicates that the current model can be used to understand predictors of linkage status (table 2).

After 12 months of baseline screening (between January and March 2019), we interviewed 167 of the 192 randomly selected individuals in detail to understand potential barriers and facilitators for non-linkage to public health facilities. The participants had overall poor knowledge about risk factors and unfavourable attitude towards availing CVD risk reduction services across all groups. Approximately three in four individual in each group were not aware about tobacco being a risk factor for hypertension, while one in two individuals was not aware about the role of obesity in diabetes and hypertension. Non-linked individuals were in denial as they considered themselves as not having risk factors, not identifying need for risk-factor modification and not identifying health-system barriers. They also reported poor family and social support. About half of those who were not linked reported that their healthcare provider did not suggest any risk reduction measure or a drug therapy for them. Most individuals who were linked to private care providers identified health-system barriers with public sector and also acknowledged that drugs in private sector are expensive. Individuals who were linked (groups A and B) identified more individual-level and health-system barriers (figure 2).

\section{DISCUSSION}

In the current study, where all individuals aged 30 years or above in the community were screened to fill the unawareness gap, 6 months later three out of five positively screened were on pharmacotherapy from either public or private sector providers. Most of those who were on medication were obtaining these from the publicsector facilities. Individuals who did not get linked to a healthcare facility were more likely to be young, with poor economic status and living farther from the UPHC. Their engagement with CHWs was also late. Those who were on pharmacotherapy identified health system as a barrier; those not linked identified more with poor reinforcement by family, peers and healthcare providers. Non-linked individuals were also twice more likely to deny presence of risk factor in them, or refusal to modify them, both being components of attitude domain. Modification in attitudes, social support, and provider reinforcement would be required to improve linkages.

Initiation of therapy for hypertension and diabetes is necessary to prevent CVDs. After initial screening for hypertension or diabetes, those detected with these 'disease conditions' need to be initiated on pharmacotherapy. Ensuring initiation of pharmacotherapy in such positively screened individuals, who are otherwise asymptomatic, is challenging. We need to overcome both internal (related to awareness and acceptability) and external (related to availability and affordability of medication) barriers to ensure initiation of preventive measures. ${ }^{10}$ Barriers that disfavour linkage can be conceptualised in reference to Andersen model of total patient delay. ${ }^{16}$ This model subdivides total delay in components like appraisal, illness, behaviour and scheduling delays. Younger, mostly asymptomatic individuals have a comparative shorter duration of diagnosis that may lead to ignorance and consequent treatment neglect. Fear of loss of control, impatience and competing priorities also force them to develop a selective blindness to self. Early CHW engagement provides a positive reinforcement so as to prompt the individual to transform from 'slack deterrent individual' to 'tense motivated individual'. Such an attitude change is a heterogeneous process, and leads to differential acceptance and continuation of various CVDprevention therapies.

Initial acceptance of pharmacotherapy and its subsequent discontinuation has been reported in literature from various high-income settings. One decade ago, it was reported from the UK that $5 \%$ of the hypertensive patients fail to initiate treatment, and about $50 \%$ default within 1 year of treatment initiation. ${ }^{16}$ Another study from Canada reported the detection-initiation gap in hypertension to be $18 \%$ and discontinuation rate to be $5 \%$ in 1 year. ${ }^{17}$ Medicare beneficiaries in the USA were reported to have about $21 \%$ annual discontinuation rate for anti-hypertensive drugs. ${ }^{18}$ Discontinuation rates for oral hypoglycaemic medication were reported to be as high as $49 \%$ at end of 1 year from another Canadian study, while re-initiation rates in the subsequent year were also high. ${ }^{19}$ There is a paucity of estimates from low-andmiddle-income country settings about such gaps in detection to initiation and characteristics of non-initiators thereon. In a hypertension adherence promotion trial from Nigeria, drop-out rates were reported to be about $12 \%$, much lower than many high-income countries. ${ }^{20}$ In our study, detection-initiation gap was high (more than $30 \%$ ), and discontinuation rate was modest at about $10 \%$ at the end of 6 months.

In the current study, those who were non-initiators were younger men compared with others. This difference may be explained by unfavourable attitudes, competing occupational priorities and gender bias towards female CHWs. This population sub-group may lack motivation for risk-modification behaviour, and their occupational engagements make it difficult for them to visit health facilities on multiple occasions for either prescription 


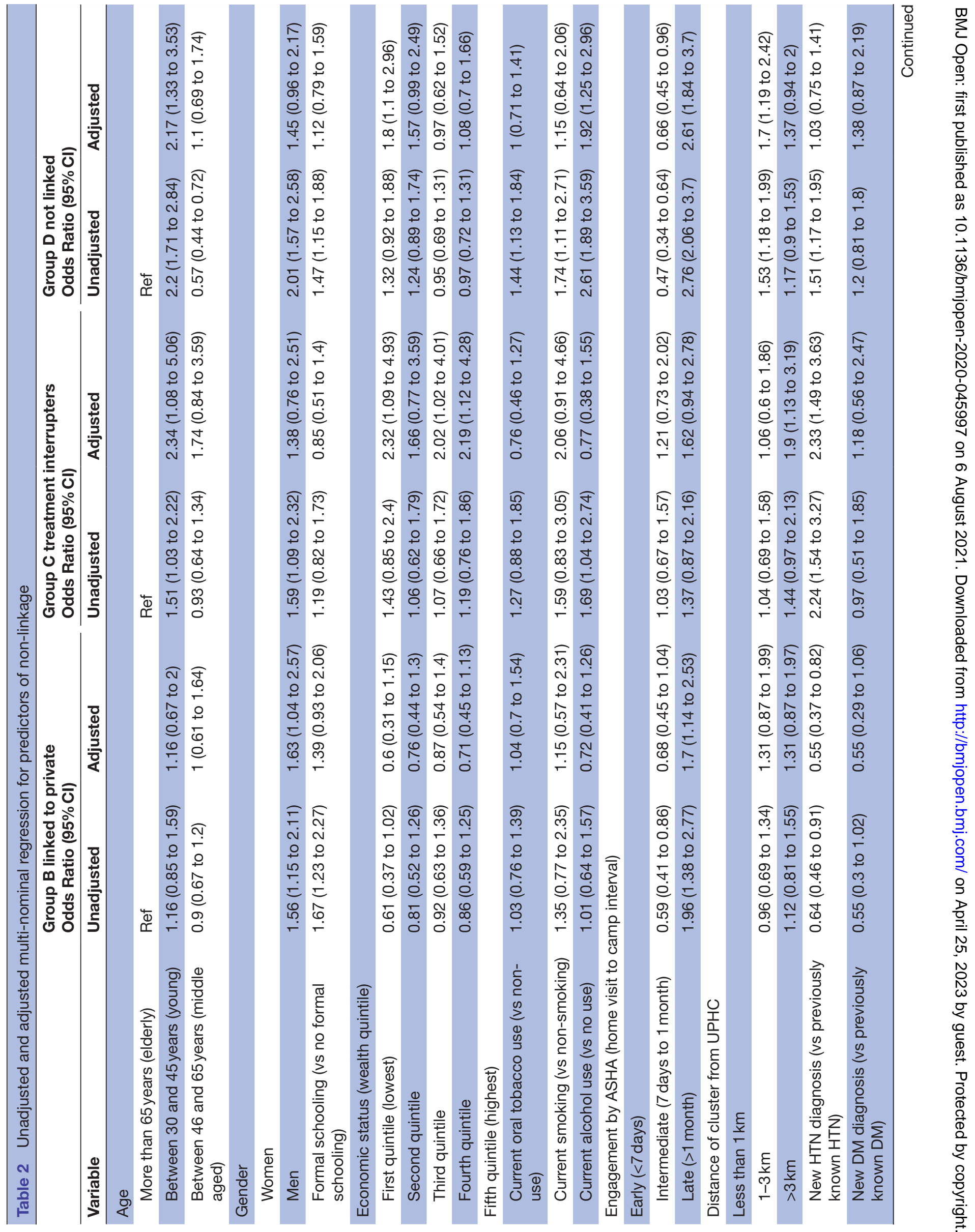


refill or disease monitoring. This population sub-group had a poor engagement with CHWs. CHWs usually visit households during the daytime, when most young men are not at home. It may also be perceived that CHWs, who are female health volunteers, cater to health issues of 'women' rather than of 'men'. Concurrently, coverage of women has been higher in screening as well as follow-up stages in our study. Measures such as evening and holiday camps, and mop-up campaign involving male volunteers were undertaken for increasing linkage of more men to health facilities for treatment initiation and continuation; however, it had limited success. Such a skewed distribution of female participation was also reported in a female CHW led trial for blood pressure reduction conducted in Nepal. $^{21}$

Prevention of CVD requires that the public health facilities should have at least three anti-hypertensive drugs (angiotensin-receptor blocker or an ACE inhibitor, calcium channel inhibitor and a thiazide diuretic), two oral hypoglycaemics (a biaguanide and a sulphonylurea), a statin and low-dose aspirin. These have also been identified by WHO-PEN as essential ingredients for non-communicable disease care. ${ }^{14}$ The WHO Package of Essential Noncommunicable Disease Interventions (WHO PEN) for primary care in low-resource settings describes a set of cost-effective interventions and resources that can be used even in resource-poor settings. Previous studies have demonstrated that availability of these medications in private pharmacies in India is comparable with high-income countries; however, households are unlikely to afford these due to lower paying capacity. ${ }^{6}$ In our study, $17.8 \%$ of high-risk individuals preferred private sector for their drug prescription, and understandably they were in higher wealth quintiles as compared with those linked to public health facilities.

Various factors influence acceptance and persistence with life-long pharmacotherapy. ${ }^{22}$ Previous studies have reported that detection-to-initiation time interval for anti-hypertensive drug therapy is longer in younger as compared with older hypertensive individuals. ${ }^{23}$ Poor economic status and poor disease control are strong predictors of discontinuation of pharmacotherapy. ${ }^{24}$ Regular medication use in chronic diseases requires a daily, lifelong, repetitive, habit-forming behaviour. Behavioural theories suggest that individuals with medication-taking habit are most likely to exhibit long-term adherence. ${ }^{25} 26$ To ensure a perpetual habit-forming behaviour, a strong early reinforcement needs to be advocated.

We need robust mechanisms to monitor adherence especially when a large number of individuals are likely to be screened and treated in public sector. ${ }^{27}$ We also need an efficient health system that ensures continual access to medication, with minimum disruption of occupational priorities. Recent guidelines for hypertension, and higher CVD risk in South Asians, advocate a more aggressive management of hypertension and diabetes mellitus. ${ }^{28}$ Various systematic reviews have recorded numerous successful interventions to overcome barriers 


\begin{tabular}{|c|c|c|c|c|c|}
\hline $\begin{array}{l}\text { Domain and Potential Barriers to effective risk } \\
\text { reduction }\end{array}$ & $\begin{array}{c}\text { Group A } \\
\text { Public Linked } \\
n=75\end{array}$ & $\begin{array}{c}\text { Group B } \\
\text { Private } \\
\text { n=22 }\end{array}$ & $\begin{array}{c}\text { Group C } \\
\text { Interrupters } \\
n=19\end{array}$ & $\begin{array}{c}\text { Group D } \\
\text { Not Linked } \\
n=51\end{array}$ & $\begin{array}{c}\text { All } \\
\mathrm{n}=167\end{array}$ \\
\hline \multicolumn{6}{|l|}{ Knowledge } \\
\hline Not aware that tobacco intake leads to HTN & 82.7 & 86.4 & 84.2 & 76.5 & 81.4 \\
\hline Not aware that Obesity leads to HTN or DM & 62.7 & 68.2 & 42.1 & 47.1 & 56.3 \\
\hline Not aware that HTN /DM can lead to heart attack/stroke & 42.7 & 59.1 & 68.4 & 39.2 & 46.7 \\
\hline Not aware that Tobacco use can be reduced & 38.7 & 36.4 & 42.1 & 33.3 & 37.1 \\
\hline Not aware that Obesity can be reduced & 25.3 & 40.9 & 15.8 & 23.5 & 25.7 \\
\hline Not aware that HTN/DM can be controlled with drugs & 8.0 & 4.5 & 0.0 & 5.9 & 6.0 \\
\hline \multicolumn{6}{|l|}{ Attitude } \\
\hline Denial of presence of risk factors & 9.3 & 13.6 & 10.5 & 29.4 & 16.2 \\
\hline Acknowledges risk but does not want to reduce & 5.3 & 9.1 & 5.3 & 27.5 & 12.6 \\
\hline Feels that risk reduction measures don't work & 5.3 & 9.1 & 0.0 & 19.6 & 9.6 \\
\hline Wants to reduce risk but not by a lifelong pill & 13.3 & 9.1 & 21.1 & 35.3 & 20.4 \\
\hline Wants to reduce risk but cannot devote time to physical & 16.0 & 36.4 & 10.5 & 27.5 & 21.6 \\
\hline Wants to reduce risk but cannot change dietary lifestyle & 4.0 & 9.1 & 5.3 & 17.6 & 9.0 \\
\hline \\
\hline My 'doctor' says that I don't need any risk reduction & 45.3 & 31.8 & 26.3 & 41.2 & 40.1 \\
\hline My 'doctor' says that I don't need any pills or medicines & 18.7 & 9.1 & 42.1 & 51.0 & 29.9 \\
\hline$\perp$ have been prescribed alternate therapv & 5.3 & 13.6 & 10.5 & 3.9 & 6.6 \\
\hline \multicolumn{6}{|l|}{ Individual } \\
\hline I sometimes forget to take drugs & 45.3 & 45.5 & 31.6 & 23.5 & 37.1 \\
\hline I sometimes forget to get a prescription refill & 24.0 & 36.4 & 21.1 & 23.5 & 25.1 \\
\hline I donot have the motivation to engage in risk reduction & 18.7 & 13.6 & 26.3 & 29.4 & 22.2 \\
\hline Lhad an adverse drug response due to medicines & 16.0 & 18.2 & 5.3 & 5.9 & 12.0 \\
\hline \multicolumn{6}{|l|}{ Health system } \\
\hline Govt health center is far away & 32.0 & 50.0 & 15.8 & 15.7 & 27.5 \\
\hline Govt health center is crowded & 45.3 & 50.0 & 26.3 & 21.6 & 36.5 \\
\hline Drugs are not available at the health center & 14.7 & 18.2 & 5.3 & 3.9 & 10.8 \\
\hline Drugs are dispensed for short period, multiple visits & 48.0 & 45.5 & 31.6 & 13.7 & 35.3 \\
\hline Drugs from govt health center are substandard & 22.7 & 9.1 & 0.0 & 11.8 & 15.0 \\
\hline Private drug stores are far away & 16.0 & 18.2 & 10.5 & 13.7 & 15.0 \\
\hline Private druas are expensive & 30.7 & 50.0 & 36.8 & 13.7 & 28.7 \\
\hline \multicolumn{6}{|l|}{ Social support } \\
\hline Family member does not want me to reduce risk & 21.3 & 18.2 & 21.1 & 33.3 & 24.6 \\
\hline Family members not willing to get medicines for me & 26.7 & 18.2 & 47.4 & 54.9 & 36.5 \\
\hline Peers believe that risk reduction does not work & 5.3 & 4.5 & 0.0 & 2.0 & 3.6 \\
\hline
\end{tabular}

Figure 2 Potential barriers for linkages to public primary-care facilities. All numbers indicate proportion of individuals in whom specified barrier is operative. This is also indicated by colour shades: shades of red (>60\%), shades of orange $(40 \%-60 \%)$, shades of yellow $(20 \%-40 \%)$ and shades of green $(0 \%-20 \%)$. A higher proportion indicates that barrier is identified in a larger number of individuals.

at individual, family, community, provider and healthsystem levels. ${ }^{29}$ Interventions that addressed barriers at multiple levels were more successful than the interventions that focused on a single or fewer barriers. ${ }^{30}$

\section{Strengths and limitations}

A key strength of the study is its implementation through stakeholders of existing public health systems who are expected to perform these activities under NPCDCS. This study was limited to urban slum clusters from a single city; however, we believe that health infrastructure is broadly similar in such settings elsewhere. All CHWs were newly trained in non-communicable disease work, while their primary training is in reproductive and child health service delivery. This new area of work for them was also a competing priority relative to their previous routine tasks in reproductive and child health domains. This limits focus of CHWs on non-communicable disease-related work, but is also a reflection of 'real-world' situation in various developing countries.

\section{CONCLUSIONS}

CHW-led strategies for screening, treatment linkage and follow-up of hypertension and diabetes for CVD reduction are feasible. However, a large gap exists between diagnosis and treatment initiation. Individuals with newly detected hypertension or diabetes would need additional reinforcement for treatment initiation and continuation. Strategies to address treatment initiation, treatment observance and treatment discontinuation need to be developed. As revealed by this study, CHWs can serve as information providers, reinforcers along with family members and an integration with system-level measures like improved accessibility, continued drug supply, newer ways of drug packaging and monitoring mechanisms may contribute to the GVD disease prevention at primary-care level.

\section{Author affiliations}

${ }^{1}$ Department of Community and Family Medicine, All India Institute of Medical Sciences, Bhopal, India

${ }^{2}$ NCD Urban Project, Department of Medicine, All India Institute of Medical Sciences, Bhopal, India

${ }^{3}$ Department of Pharmacology, All India Institute of Medical Sciences, Bhopal, India ${ }^{4}$ All India Institute of Medical Sciences, Bhopal, India

${ }^{5}$ Department of Medicine, All India Institute of Medical Sciences, Bhopal, India

Contributors RJ conceived the study; RJ, AP and SK developed the protocol; RA, KD, IRT, VM and NS acquired data; AJ, SA, SK, AP and RJ supervised data acquisition and verified diagnosis; AP, AJ and RJ analysed data and wrote the first draft. All authors critically reviewed the first draft and provided inputs for its revisions.

Funding This study was funded by the Indian Council of Medical Research, New Delhi as an extramural project grant (Principal Investigator-RJ, IRIS-2014-0976).

Disclaimer The funders had no role in data collection, analysis and writing of the manuscript.

Competing interests None declared.

Patient consent for publication Not required.

Ethics approval The study design was approved by the Institutional Human Ethics Committee of All India Institute of Medical Sciences, Bhopal (Ref: IHEC-LOP/2017/ EF00045).

Provenance and peer review Not commissioned; externally peer reviewed. 
Data availability statement Data are available on reasonable request. Raw data of this study are not deposited in any public repository. However, anonymised raw data of this study would be available to academicians or researchers on request to the corresponding author.

Supplemental material This content has been supplied by the author(s). It has not been vetted by BMJ Publishing Group Limited (BMJ) and may not have been peer-reviewed. Any opinions or recommendations discussed are solely those of the author(s) and are not endorsed by BMJ. BMJ disclaims all liability and responsibility arising from any reliance placed on the content. Where the content includes any translated material, BMJ does not warrant the accuracy and reliability of the translations (including but not limited to local regulations, clinical guidelines, terminology, drug names and drug dosages), and is not responsible for any error and/or omissions arising from translation and adaptation or otherwise.

Open access This is an open access article distributed in accordance with the Creative Commons Attribution Non Commercial (CC BY-NC 4.0) license, which permits others to distribute, remix, adapt, build upon this work non-commercially, and license their derivative works on different terms, provided the original work is properly cited, appropriate credit is given, any changes made indicated, and the use is non-commercial. See: http://creativecommons.org/licenses/by-nc/4.0/.

\section{ORCID iDs}

Abhijit Pakhare http://orcid.org/0000-0003-2897-4141

Ankur Joshi http://orcid.org/0000-0002-3766-376X

Sanjeev Kumar http://orcid.org/0000-0003-2730-2378

Rajnish Joshi http://orcid.org/0000-0002-4702-0522

\section{REFERENCES}

1 Olsen $\mathrm{MH}$, Angell SY, Asma S, et al. A call to action and a lifecourse strategy to address the global burden of raised blood pressure on current and future generations: the Lancet Commission on hypertension. The Lancet 2016;388:2665-712.

2 Gupta R, Gupta VP, Prakash H, et al. 25-Year trends in hypertension prevalence, awareness, treatment, and control in an Indian urban population: Jaipur Heart Watch. Indian Heart J 2018;70:802-7.

3 Anjana RM, Deepa M, Pradeepa R, et al. Prevalence of diabetes and prediabetes in 15 states of India: results from the ICMR-INDIAB population-based cross-sectional study. Lancet Diabetes Endocrinol 2017;5:585-96.

4 Chow CK, Teo KK, Rangarajan S, et al. Prevalence, awareness, treatment, and control of hypertension in rural and urban communities in high-, middle-, and low-income countries. JAMA 2013;310:959-68.

5 DGHS M Gol. National programme for prevention and control of cancer, diabetes, cardiovascular diseases and stroke (NPCDCS), 2019. Available: https://dghs.gov.in/content/1363_3_NationalProg rammePreventionControl.aspx

6 Attaei MW, Khatib R, McKee M, et al. Availability and affordability of blood pressure-lowering medicines and the effect on blood pressure control in high-income, middle-income, and low-income countries: an analysis of the PURE study data. Lancet Public Health 2017:2:e411-9.

7 Nieuwlaat R, Schwalm J-D, Khatib R, et al. Why are we failing to implement effective therapies in cardiovascular disease? Eur Heart $J$ 2013:34:1262-9.

8 Dalal J, Sethi KK, Guha S, et al. Screening for hypertension in asymptomatic individuals in India: an expert consensus statement. $J$ Assoc Physicians India 2020;68:73-9.

9 Souffront K, Gestal C, Melkus Gail D'Eramo, et al. Recognition of asymptomatic hypertension in an urban emergency department: where are we now? Adv Emerg Nurs J 2016;38:320-6.

10 Schwalm JD, McKee M, Huffman MD, et al. Resource effective strategies to prevent and treat cardiovascular disease. Circulation 2016;133:742-55.
11 Pakhare AP, Joshi A, Khadanga S. Feasibility of community health worker based cardiovascular risk reduction strategies in urban slums of Bhopal: rationale and design of community based study. medRxiv 2020.

12 AJMC. The JNC 8 hypertension guidelines: an in-depth guide, 2019. Available: https://www.ajmc.com/journals/evidence-based-diabetesmanagement/2014/january-2014/the-jnc-8-hypertension-guidelinesan-in-depth-guide

13 American Diabetes Association. Standards of medical care in diabetes - 2017: summary of revisions. Diabetes Care 2017;40:S4-5.

14 Essential Medicines and Health Products Information Portal A World Health Organization resource. Package of essential noncommunicable (PEN) disease interventions for primary health care in low-resource settings, 2019. Available: https://apps.who.int/ medicinedocs/en/m/abstract/Js19715en/

15 Rutstein SO. Steps to constructing the new DHS wealth index, 2019. Available: https://dhsprogram.com/programming/wealth\%20index/ Steps_to_constructing_the_new_DHS_Wealth_Index.pdf

16 Neupane D, McLachlan CS, Mishra SR, et al. Effectiveness of a lifestyle intervention led by female community health volunteers versus usual care in blood pressure reduction (COBIN): an openlabel, cluster-randomised trial. Lancet Glob Health 2018;6:e66-73.

17 Vrijens B, Vincze G, Kristanto P, et al. Adherence to prescribed antihypertensive drug treatments: longitudinal study of electronically compiled dosing histories. BMJ 2008;336:1114-7.

18 Gee ME, Campbell NRC, Gwadry-Sridhar F, et al. Antihypertensive medication use, adherence, stops, and starts in Canadians with hypertension. Can J Cardiol 2012;28:383-9.

19 Tajeu GS, Kent ST, Kronish IM, et al. Trends in antihypertensive medication discontinuation and low adherence among Medicare beneficiaries initiating treatment from 2007 to 2012. Hypertension 2016;68:565-75

20 Simard P, Presse N, Roy L, et al. Persistence and adherence to oral antidiabetics: a population-based cohort study. Acta Diabetol 2015;52:547-56.

21 Adeyemo A, Tayo BO, Luke A, et al. The Nigerian antihypertensive adherence trial: a community-based randomized trial. J Hypertens 2013;31:201-7.

22 Hargrove JL, Pate V, Casteel CH, et al. Antihypertensive adherence trajectories among older adults in the first year after initiation of therapy. Am J Hypertens 2017;30:1015-23.

23 Johnson HM, Thorpe CT, Bartels CM, et al. Antihypertensive medication initiation among young adults with regular primary care use. J Gen Intern Med 2014;29:723-31.

24 Sankar UV, Lipska K, Mini GK, et al. The adherence to medications in diabetic patients in rural Kerala, India. Asia Pac J Public Health 2015;27:NP513-23.

25 Durand H, Hayes P, Harhen B, et al. Medication adherence for resistant hypertension: assessing theoretical predictors of adherence using direct and indirect adherence measures. Br J Health Psychol 2018;23:949-66.

26 Lauffenburger JC, Franklin JM, Krumme AA, et al. Predicting adherence to chronic disease medications in patients with long-term initial medication fills using indicators of clinical events and health behaviors. J Manag Care Spec Pharm 2018;24:469-77.

27 Basu S, Garg S, Sharma N, et al. Improving the assessment of medication adherence: challenges and considerations with a focus on low-resource settings. Ci Ji Yi Xue Za Zhi 2019;31:73-80.

28 Wander GS, Gupta R, S Ram CV. Western guidelines bring in cardiovascular risk prediction along with blood pressure levels for initiation of antihypertensive drugs: is the pitch ready for Indians.... J Hum Hypertens 2019;33:566-7.

29 Bharti S, Bharti B. Adherence to antihypertensive therapy: a missing link between treatment and outcomes. Am J Hypertens 2018;31:290-2.

30 Conn VS, Ruppar TM, Chase J-AD, et al. Interventions to improve medication adherence in hypertensive patients: systematic review and meta-analysis. Curr Hypertens Rep 2015;17:94. 